\title{
The "Dumbing-Down” and Selling Out of Corporate Human Resources: A Strategic Challenge to Organizations and their Leaders
}

\section{Virgil Berry $\mathbf{J r}^{\star}$}

Senior Partner, Organization Strategies Intl, USA

*Corresponding author: Virgil Berry Jr, Senior Partner, Organization Strategies Intl, USA, Tel: 888-248-4448; E-mail: sfreeman@osiconsulting.com

Received date: November 06, 2015, Accepted date: May 10, 2016, Published date: May 20, 2016

Copyright: (c) 2016 Berry V Jr. This is an open-access article distributed under the terms of the Creative Commons Attribution License, which permits unrestricted use, distribution, and reproduction in any medium, provided the original author and source are credited.

\begin{abstract}
Few business functions have been subjected to more political change or controversy than Human Resources. Brand Voice/ADP conducted a study that reported on the "State of Human Resources" with disappointing results. This article serves to provide one explanation of what is behind those results and how recent changes in the HR function have only served to fail leaders and their organizations.
\end{abstract}

Keywords: Human resources; Organizations; Entrepreneurship

\section{Introduction}

Brand Voice/ADP conducted a study entitled "The State of Human Resources - A Guide to the HR Galaxy" with published results in Forbes (May 25, 2015). The results were disappointing, but not surprising, as they reflected a clear lack of satisfaction by CEOs and other business leaders with the current state of human resources as a profession. They may be explained by a different set of numbers which reveal why HR does not measure up to expectations. Organization Strategies Intl. undertook a study utilizing Reference USA to determine what was behind the numbers in the Forbes article. We researched the HR demographics of companies by size across ten US states around the country as well as in Canada and Europe. We discovered the following:

- Ninety-four percent (94\%) of companies with revenues from $\$ 5 \mathrm{M}$ to $\$ 100 \mathrm{M}$ had female VPs/Directors of HR.

- Eighty-three percent (83\%) of CHRO's in companies ranging from $\$ 101 \mathrm{M}$ to $\$ 1 \mathrm{~B}$, were female. Fifty-eight percent $(58 \%)$ of those companies had HR staffs composed entirely of females.

- In companies over $\$ 1 \mathrm{~B}$, females made up seventy-four $(74 \%)$ of CHROs. Males seemed to be limited to the compensation or HR IT roles within HR and almost all of the male CHROs served in industrial companies (usually with a unionized labor force), indicating a different bias, though that is changing.

- As best we could determine by calls to many of these companies, ninety-one percent (91\%) of replacements for female CHROs was another female going back two and three hires.

A similar percentage of replacements for male CHROs were female.

In over eighty-nine percent $(89 \%)$ of Silicon Valley companies surveyed, there have been female CHROs going back at least two hires with more than half of the companies having no male CHROs at any time in their history. In the Washington DC area (which has become a technology and non-profit hub), ninety two percent (92\%) of CHROs are females. We found that ninety-seven (97\%) of non-profits in DC had female CHROs. The overwhelming majority of those HR departments were staffed entirely by females. A similar pattern emerged when we looked at thirty Canadian companies ranging in size from $\$ 10 \mathrm{M}$ to $\$ 1 \mathrm{~B}+$ and twenty-five European companies within the same range.

Nevertheless, when we looked at senior corporate rosters under $\$ 1 B$, in our study, we found that only six percent $(6 \%)$ of CEOs were female and the vast majority of other senior executive roles were filled by males. Nevertheless, in most of these companies, the VP or Director of HR was not even listed on the corporate senior executive roster when looking at their web sites or using

Business Week, It has been a long stated fact in HR that work environments and management teams that are not diversified are usually underperforming. Apparently, that does not apply to Human Resources. What is Behind This Latest Shift in HR?

\section{Politics and Political Correctness}

Unlike other corporate functions, the HR function has gone through a number of political changes since World War II ranging from labor busting in the fifties and sixties, to labor relations in the seventies, to a strategic focus in the 80s and 90s with the rise of such disciplines as succession planning, leadership development and organization effectiveness capabilities being incorporated into HR. Those more strategic disciplines were necessitated with the advent of the age of radical change as traditional management and business practices could not keep up with radically changing business conditions that have been impacting businesses. The usual fads and fix its traditional business planning, down-sizing and outworn management and leadership practices were failing.

Much of the politics have been based on political correctness which marks the current phase of woman breaking into the corporate management ranks, principally in the HR function (and a couple other staff roles such as marketing). Unfortunately, that has backfired as HR has become a dead end for females in the business world. HR is now recognized as the "women's department" in too many companies. As a result, employees within organizations do not respect the work of the $\mathrm{HR}$ function as it has become a gender based (and frequently biased) function focused mainly on personnel administrative duties which are frequently perceived as being burdensome to the workforce. Misandry has also become an increased factor as female CHROs and their female staffs have rejected, out of hand, male consultants and are imposing the 
same prejudicial attitudes towards male workers as was imposed on females in the past. Increasingly, males are now utilizing legal remedies to protect their rights in the work place.

Corporate boards have been correctly criticized for not admitting more women to the ranks of senior management. This has resulted in law suits and negative publicity for companies. Companies started hiring females to the top HR role as a means for showing that they were on the right side of the political correctness issue. Nevertheless, the ranks of senior management and boards of the overwhelming majority of companies continue to be populated almost exclusively by males.

\section{SHRM}

The Society for Human Resource Management (SHRM) has contributed significantly to this latest trend in human resources. SHRM has made it nearly mandatory for HR managers and CHROs to have SHRM certification before companies can hire them despite the college and graduate degrees in HR management that many if not most HR professionals have earned. SHRM's requirements focus on fourteen areas of "concentration" in what may be termed "personnel administrative areas" with only one focusing on a strategic core area, by comparison (despite recently purchasing the Human Resource Planning Society, widely regarded as the Strategic HR wing of the profession). A colleague of mine submitted a book proposal to SHRM's book publishing division. It appropriately focused the first half of the book on understanding corporate culture and change from a strategic perspective with the back half of the book devoted to processes for instituting change. They rejected it because they did not want the strategic explanation in the first half of the book-just "how to steps" from the second half.

SHRM's internal staff and management are also dominated by females (and have refused to publish articles like this in their own publications). This clearly speaks to the Forbes article that shows minimal contributions in such strategic areas as talent management, strategic influence on CEOs and other corporate leaders, and recognizing trends (i.e. change strategy). If SHRM did not invent the term "HR generalist" (the antithesis of a strategic perspective) then it certainly institutionalized it. No other professional discipline has the term, but many other disciplines have specialists which denote a concentrated or elevated level of expertise and ability, by comparison. We have turned our HR executives and managers into personnel secretaries or administrators at best, who have little strategic leverage within the organization. Neither has this move to a politically correct HR function made company work forces that much more diverse.

\section{The Demise of the Strategically Focused HR Function}

Just as disturbing has been the demise of the more strategic disciplines of organization effectiveness (OD), change management, leadership/management development and succession planning that were implied in the Forbes article.

In our study, more than seventy-one percent (71\%) of top organization effectiveness executives lacked a graduate degree in OD or a closely related discipline. This may explain why the study reflected a lack of HR analytics. This role once required a doctorate or at the least a master's degree to properly serve management as this profession requires a good deal of expertise in behavior analysis and management, human performance and the ability to understand the functioning of organizations in light of changing business conditions.
OSI also approached the CHRO officer of Hilton Hotels several years ago to speak at a conference we were sponsoring on the strategic aspects of HR. We also asked if we could conduct an abbreviated, pro bono, corporate culture bench marking survey to add Hilton's data (as a strong service culture) to our firm's bench marking data base. His female VP of Organization Development vetoed both. She had only a bachelor's degree in marketing (and no experience in the discipline of organization effectiveness).

The same role at Angie's List is held by a female who has only a bachelor's degree in a field that did not qualify her for that role and her title is "Director of Organization Happiness", which clearly trivializes a key strategic capability. The company is now facing problems that reflect serious issues with its organization and management performance in relation to changing business conditions for Angie's List. She and her female CHRO vetoed a similar study while their CEO, Mark Howell, refused to overrule them. One exception was earlier this century when Green Mountain Coffee Roasters Founder/ CEO, Bob Stiller, overruled his female VP of HR, Kathy Brooks, who resisted a similar study at all costs and then attempted to undermine it while it was being conducted. Neither could Brooks understand why she could not recruit males to her all-female HR department. GMCR has had a succession of four straight female CHROs. What message does send.

When we approached the CHROs of eleven leading high technology companies to speak at a conference on corporate culture within their companies, not one accepted. Actually, not one even replied to our invitation after we first sent the invitation through their CEOs. Interestingly, every one of the CHROs was female. Some, such as the SVP of HR at Red Hat, Delisa Alexander, were actually hostile to the invitation.

Several years ago, my firm was approached by the Nature Conservancy's female Director of HR to train their newly hired, female director of OD who had no qualifications for the role. Needless to say, we declined. Before its acquisition by Deutsche bank, Bankers Trust asked us to train their newly assembled OD department. It was comprised entirely of women. None had a background in business much less degrees related to organization or leadership development or any other business discipline. It was too little too late as Bankers Trust had to be rescued by Deutsche Bank as a result of their failed corporate culture.

A colleague of mine went through an arduous selection process to fill the position of Division Director of Organization Effectiveness at Merck. He had exceptional academic qualifications as well as more than two decades of high level consulting and corporate experience in major companies. He earned a score of 93 points out of 100 for the graded interview process with his next closest competitor earning a score in the sixties. Nevertheless, the incoming SVP of HR, Betsy Smith (who had just six months of experience in HR at her previous company before being dismissed from that role) decided to void the offer that Merck made to him because "I think that department needs more women." The department had twelve people. Only two were males with just one (a male) having an advanced academic degree and experience in the field. The remainder of the department was made up of ten women who had been downsized to the OD function from marketing, research and legal. I have never seen HR professionals downsized to finance, legal or other fields within a company.

We are also seeing real opposition by the HR department, itself, to undertaking badly needed strategic initiatives by outside experts when 
they lack the internal capabilities in such areas as change management, organization performance, succession planning and leadership development. When one of my partners interviewed John Tracy, CEO of $\$ 4 \mathrm{~B}+\mathrm{DOT}$ Foods for an article, they went to the subject of succession planning. Tracy was sure that they had a solid succession planning process, but on further examination it was clear that they were just doing the usual end of the year performance appraisal. Their VP of HR refused to allow a pro bono bench marking study and he had convinced Tracy and the rest of DOT Food's executive team that they were doing succession planning-which they were not. At Martins Supermarkets (a division of Ahold USA), the VP of HR prevented the new President, Tom Lenkevich, from going forward with a strategically focused conference for senior management on organization performance and change as it related to the company. Further examination revealed that the company had no "OD" capabilities, which showed in the overly centralized and bureaucratic functioning of the company. HR in these two companies clearly lacked a strategic focus.

Franklin Electric's CEO John Sengstack, referred our firm to their CHRO officer, Tom Strupp regarding a study which would yield empirical data via a systematic data gathering process across several areas of strategic organization performance. Strupp was dead set against the "numbers driven study" which surprised us since he was previously the company's CFO. This is another example of the one-way street between HR and the rest of the corporation and how competence, qualifications and experience in HR are not valued.

Former CEOs like George Fisher of Motorola, Louis Gerstner of IBM, James Burke and William Lawler of Johnson and Johnson as well as Rich Teerlink of Harley Davidson relied heavily on their Chief Human Resource Officers and their HR functions, for a wide range of in-depth and strategic issues not just for hiring, firing and compensation issues. Many HR functions also retained top executives with PhDs, and at least Masters Degrees, which were required to deal with the sophisticated issues of corporate culture and management performance. A number of CHRO's even had their doctorates in that period. Those kinds of people are rarely found in corporate HR today.

\section{How to Get More Out of the Human Resource Function}

If companies (and non-profits) want to improve the performance of their HR functions, they need to do several things:
- Hire on the basis of merit which HR is supposed to ensure for the larger business organization.

- Look for balance in HR departments rather than allow them to be staffed on the basis of gender or ethnic politics. HR should not become a legacy function for any particular demographic group.

- Apply a strategic focus for the HR function. It is critical to building capabilities in the change management, organization and leadership performance function by employing the best educated and most experienced people. This is especially important for emerging companies that require talent and organization direction when dealing with overwhelming change issues. There are a number of excellent graduate school programs in organization development around the country. Some say that the strategically focused "OD" and leadership capabilities should not even be part of the more bureaucratic and administrative HR function but should be a separate function unto itself as it once was at Johnson and Johnson or where it was part of the strategy department at the former Montgomery Ward (aligned too late to benefit that company).

- Hire middle and senior level HR managers who understand business as well as HR/personnel duties making sure that they gain a strategic focus of the business and industry.

- Move the top CHRO officer to the executive council. Smaller companies should not diminish the role to one of just hiring, firing and administering health benefits cutting them off from other decision makers who need their input.

Companies have to wean themselves away from the dictates of SHRM, unless they just want a personnel administrative function that will perpetuate the numbers in the May 25 Forbes article.

While identifying changing business conditions requires HR to identify those trends to anticipate future needs in talent and head count, most HR departments cannot do that as they have been turned into personnel processing departments with no strategic capabilities. "The HR Guide to the Galaxy-The State of Human Resources" Forbes, May 25, 2015. 